\title{
Screening for Chemosensitizers from Natural Plant Extracts through the Inhibition Mechanism of P-glycoprotein
}

\author{
Hee-Jeong Ahn and Im-Sook Song ${ }^{\dagger}$ \\ Department of Pharmacology and Pharmacogenomics Research Center, \\ Inje University College of Medicine, Busan 614-735, Korea \\ (Received July 14, 2010 • Revised October 4, 2010 • Accepted October 5, 2010)
}

\begin{abstract}
P-gp plays a critical role in drug disposition and represents a mechanism for the development of multidrug resistance. Flavonoids, a major class of natural compounds widely present in foods and herbal products, have been shown to inhibit P-gp. Therefore, the aim of this study was to identify new candidate chemosensitizers by screening various plant extracts. The ability of natural plant extracts to inhibit P-gp activity was assessed by measuring cellular accumulation of calcein AM, daunorubicin and vincristine in P-gp overexpressing MDCKII-MDR1 cells. Among more than 800 plant extracts, eight were found to inhibit P-gp activity. Curcuma aromatica extract produced greatest inhibition, followed by Curcuma longa and Dalbergia odorifera extracts. Extracts of Aloe ferox, Curcuma zedoariae rhizome, Zanthoxylum planispinum, and Ageratum conyzoides showed moderate inhibitory effects. Curcumin and quercetin exhibited similar inhibition of P-gpmediated efflux of daunorubicin and vincristine, and flavones had a lesser effect. When chemosensitizing effect was evaluated by measuring daunorubicin sensitivity to MDCKII-MDR1 cells in the presence of natural plant extracts, Curcuma aromatica showed the most potent chemosensitizing effect based on daunorubicin cytotoxicity. In conclusion, natural plant extracts such as Curcuma aromatica can potently inhibit P-gp activity and may have potential as a novel chemosensitizers.
\end{abstract}

Key words - Natural plant extracts, Curcuma aromatica, P-gp inhibitors, Chemosensitizer

Multidrug resistance (MDR) can develop in tumor cells that have been exposed to a cytotoxic agent. This cross-resistance of tumor cells to a range of structurally and functionally unrelated compounds present a significant obstacle to successful chemotherapy for many cancers (Thomas and Coley, 2003). Strategies for circumventing MDR include the administration of combination therapy with MDR inhibitors and the development of new anticancer drugs that are not susceptible to MDR (Tan et al., 2000; Efferth et al., 2002).

P-glycoprotein (P-gp) is an ATP-dependent efflux pump responsible for the efflux of anticancer drugs from inside of the cells, and P-gp overexpression is reportedly a major molecular mechanism underlying the development of MDR (Bansal et al., 2009). Accordingly, many P-gp inhibitors such as valspodar (PSC833), tariquidar (XR9576), zosuquidar (LY335979) and elacridar (GF120918) have been extensively studied as MDR modulators.

Three generations of P-gp inhibitors have been developed, and they vary in specificity or affinity for P-gp (Bansal et al., 2009; Krishna and Mayer, 2000). First generation P-gp inhibitors are pharmacological compounds, which have been used

\footnotetext{
Corresponding Author :

Tel : +82-51-890-8664, E-mail : issong@inje.ac.kr

DOI : $10.4333 /$ KPS.2010.40.5.269
}

originally for other indications but shown to inhibit P-gp function. These compounds, including verapamil, quinidine and cyclosporin A (CsA), tend to be non-selective and less potent, and their use is generally limited by toxicity at the high serum concentrations required to effectively inhibit P-gp (Dantzig et al., 2003). Second generation P-gp inhibitors have higher affinities for P-gp and thus avoid the non-specific effects of the first-generation compounds. Examples of these compounds include valspodar (PSC833) and dexverapamil. Although these compounds were developed with the aim of being less toxic than the first generation drugs, most second generation modulators are also cytochrome P450 3A4 (CYP3A4) substrates and often result in unpredictable pharmacokinetic interactions affecting the metabolism and/or clearance of coadministered drugs (Liscovitch and Lavie, 2002). Structure-activity relationships and combinational chemistry approaches have guided the development of novel third-generation P-gp inhibitors. These compounds have high affinity for P-gp, are not metabolized by CYP3A4, and do not alter the pharmacokinetics of co-administered anticancer drugs (Bansal et al., 2009). Clinical trials using third-generation P-gp inhibitors such as tariquidar, alacridar and zosuquidar have produced encouraging results in phase I and II studies with anticancer drugs. However, phase III trials of some of these agents have been unsuccessful, and no significant survival benefit of P-gp 
inhibition has yet been demonstrated (Liscovitch and Lavie, 2002; Ozben, 2006).

The first report documenting the effects of P-gp inhibition described the interactions of grapefruit juice with a variety of drugs (Bailey et al., 1991). Since then, both beneficial and harmful pharmacokinetic interactions have been attributed to herbal supplements (Marchetti et al., 2007; Zhou et al., 2004). Among the potentially beneficial effects is the improvement of pharmacokinetic profiles of coadministered drugs through enhanced bioavailability, increased tissue accumulation, decreased excretion clearance, or modulation of MDR. In recent years, various pharmaceutical excipients and herbal supplements have emerged as potential alternatives to currently used P-gp inhibitors (Deferme and Augustijns, 2003; Deferme et al., 2002; Zhou et al., 2004). The safety of many herbs has been demonstrated by a long and continuous history of dietary use, making some herbal supplements ideal candidates for MDR modulation.

Thus, to identify new candidate chemosensitizers, we screened more than 800 natural plant extracts used in Korea and China for P-gp inhibition by examining cellular accumulation of calcein AM in P-gp overexpressing cells and evaluated chemosensitizing effect of natural plant extracts using daunorubicin sensitivity to P-gp overexpressing cells.

\section{Materials and Methods}

\section{Materials}

Natural plant extracts were provided from Plant Extract Bank (http://extract.pdrc.re.kr, Daejeon, Korea). Natural plant materials were washed, shade dried and crushed. The crushed materials were extracted with $95 \%$ ethanol at $50^{\circ} \mathrm{C}$. The extracts were concentrated under reduced pressure at $45^{\circ} \mathrm{C}$ and kept in the refrigerator.

Mardin-Darby canine kidney II (MDCKII)-mock and MDCKIIMDR1 cells were obtained from Dr. A.H. Schinkel (Netherlands Cancer Institute, Amsterdam, The Netherlands). Cyclosporin A (CsA), para-aminohippuric acid (PAH), quercetin, and MTT (3-(4,5-Dimethylthiazol-2-yl)-2,5-diphenyltetrazolium bromide) were purchased from Sigma-Aldrich Chemicals (St. Louis, $\mathrm{MO}$ ) and calcein AM were purchased from Invitrogen (Carlsbad, CA). Curcumin and flavone were purchased from ICC Chemical Co. (New York, NY). $\left.{ }^{3} \mathrm{H}\right]$ Vincristine $(9.6 \mathrm{Ci} /$ mmol) and $\left[{ }^{3} \mathrm{H}\right]$ daunorubicin $(4.4 \mathrm{Ci} / \mathrm{mmol})$ were purchased from Perkin Elmer Inc. (Boston, MA).

\section{Western blot analysis}

MDCKII-mock and MDCKII-MDR1 cells were maintained at $37^{\circ} \mathrm{C}$ in a humidified atmosphere of $5 \% \mathrm{CO}_{2} / 95 \%$ air, in Dulbecco's modified Eagle's medium supplemented with $10 \%$ fetal bovine serum, $2 \mathrm{mM}$ L-glutamine, and $100 \mathrm{U} / \mathrm{mL}$ penicillin-streptomycin. The cells were harvested by centrifugation at $6,000 \mathrm{rpm}$ for $3 \mathrm{~min}$ at $4^{\circ} \mathrm{C}$ and cell pellets were swollen in one volume of lysis buffer [50 mM Tris-Cl pH 7.4, 1\% NP$40,0.25 \%$ sodium deoxycholate, $0.1 \% \mathrm{SDS}, 150 \mathrm{mM} \mathrm{NaCl}$, $1 \mathrm{mM}$ EDTA, and protease inhibitor] for $10 \mathrm{~min}$. Aliquots that contained $30 \mu \mathrm{g}$ of protein were separated by SDS-polyacrylamide gel electrophoresis in a 4-12\% gradient gel (Invitrogen) and transferred to nitrocellulose membranes (Bio-Rad, Hercules, CA). The membranes were blocked with 5\% nonfat milk and probed with anti-P-gp (Santa Cruz Biotechnology, Santa Cruz, CA), and anti-actin antibodies (Cell Signaling Technology, Beverly, MA). The membranes were then incubated with horseradish peroxidase-conjugated anti-rabbit IgG (Santa Cruz Biotechnology) and visualized using the enhanced chemiluminescence system (Santa Cruz Biotechnology).

\section{Intracellular calcein accumulation assay in MDCKII- MDR1 cells}

The intracellular accumulation of calcein was measured using the cell marker reagent calcein acetoxymethyl ester (calcein AM, Sigma Aldrich). The cells were incubated with calcein $\mathrm{AM}(0.5 \mu \mathrm{M})$ at $37^{\circ} \mathrm{C}$ for $30 \mathrm{~min}$ in the presence of $10 \mu \mathrm{g} /$ $\mathrm{mL}$ natural plant extracts, and accumulation was halted after 30 min by rapidly washing the cells three times with ice-cold PBS. The cells were then lysed by incubation with $250 \mu \mathrm{L}$ of $1 \%$ Triton X-100 (Sigma Aldrich) in PBS for $1 \mathrm{~h}$. A $200 \mu \mathrm{L}$ aliquot of cell lysate was transferred into a 96-well plate, and the fluorescence due to intracellular calcein was measured using a Victor3 plate reader (Perkin-Elmer LAS, Waltham, MA) with excitation and emission wavelengths of 485 and 535 $\mathrm{nm}$, respectively. A Bradford protein assay kit (Bio-Rad) was used to determine the amount of cellular protein in each lysate. CsA and PAH were used as a positive and a negative control, respectively, for this assay.

The effect of natural plant extracts on the cellular accumulation of daunorubicin and vincristine in MDCKIIMDR1 cells

To screen the effect of natural plant extracts on the cellular accumulation of P-gp substrate anti-cancer drugs, daunorubicin and vincristine, $10^{4}$ cells were seeded in 96-well plates. After the cells reached $95 \%$ confluence, the growth medium was discarded and the attached cells were washed and preincubated with Dulbecco's phosphate buffered saline (DPBS) supplemented with $20 \mathrm{mM}$ glucose, $9 \mathrm{mM}$ sodium bicarbon- 
ate, and $25 \mathrm{mM}$ Hepes for $30 \mathrm{~min}$ at $37^{\circ} \mathrm{C}$. The uptake of $\left[{ }^{3} \mathrm{H}\right]$ daunorubicin $(0.1$ and $1 \mu \mathrm{M})$ and $\left[{ }^{3} \mathrm{H}\right]$ vincristine $(0.1$ and $1 \mu \mathrm{M})$ was initiated by the addition, to the cells, of medium containing $10 \mu \mathrm{g} / \mathrm{mL}$ natural plant extract, followed by incubation at $37^{\circ} \mathrm{C}$ for $30 \mathrm{~min}$. The cells were washed three times with $1 \mathrm{~mL}$ of ice-cold DPBS immediately after placing the plates on ice. The radioactivity of $\left[{ }^{3} \mathrm{H}\right]$ daunorubicin and $\left[{ }^{3} \mathrm{H}\right]$ vincristine in the cells were measured by liquid scintillation counting after incubating the cells in $50 \mu \mathrm{L}$ of cell lysis reagent $\left(100 \mathrm{mM} \mathrm{KH} \mathrm{PO}_{4}, 1 \mathrm{mM}\right.$ EDTA, $7 \mathrm{mM}$ 2-mercaptoethanol, $1 \%$ Triton $\mathrm{X}-100$, and $10 \%$ glycerol, $\mathrm{pH} 7.8$ ).

\section{Cell viability test with natural plant extracts}

Cells grown in 96 well plates $\left(10^{4}\right.$ cells $/$ well $)$ were incubated in the absence and the presence of 5 and $10 \mu \mathrm{g} / \mathrm{mL}$ herbal constituents or natural plant extracts for $48 \mathrm{~h}$. Then, $200 \mu \mathrm{L}$ of MTT $(0.5 \mathrm{mg} / \mathrm{mL})$ was added to each well, and the plate was incubated for $4 \mathrm{~h}$. The medium was removed and the purple formazan products were solubilized with $120 \mu \mathrm{L}$ dimethyl sulfoxide. The cell contents were measured by the absorbance at $570 \mathrm{~nm}$. Cell viability was indicated as a percentage of live cells compared with control group after the background correction.

Determination of daunorubicin sensitivity in the presence of natural plant extracts

Cells grown in 96 well plates $\left(10^{4}\right.$ cells/well) were continuously exposed to various concentrations of daunorubicin $(0.01-50 \mu \mathrm{M})$ with or without $10 \mu \mathrm{g} / \mathrm{mL}$ herbal constituents or natural plant extracts for $48 \mathrm{~h}$. After the $48 \mathrm{~h}$ incubation, $200 \mu \mathrm{L}$ of MTT $(0.5 \mathrm{mg} / \mathrm{mL})$ was added to each well, and the plate was incubated for $4 \mathrm{~h}$. The medium was removed and the formazan products were solubilized with $120 \mu \mathrm{L}$ dimethyl sulfoxide. The cell contents were measured by the absorbance at $570 \mathrm{~nm}$. The $\mathrm{IC}_{50}$ value $(\mu \mathrm{M})$ was calculated by the Hill plot method using WinNonlin software (ver 5.1, Pharsight, Mountain View, CA).

\section{Results}

Inhibitory effect of natural plant extracts on P-gp mediated efflux

First, we characterized the expression and functionality of Pgp transporters in MDCKII-MDR1 cells. P-gp overexpression in MDCKII-MDR1 cells was confirmed by Western blot analysis as described in Methods. The expression level of P-gp in the cells was much greater than that in MDCKII-mock cells (Fig. 1). To evaluate the functionality of P-gp in MDCKII-

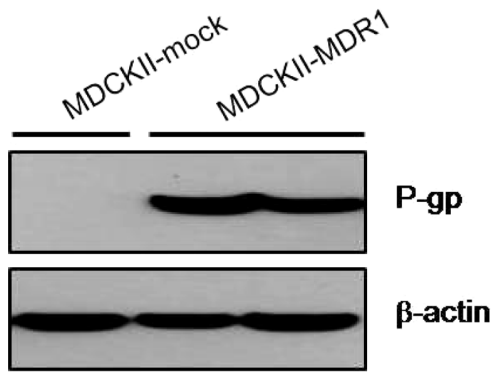

Figure 1. Western blot analysis of MDCK cells that stably express MDR1. Lane 1 represents vector-transfected control cells (MDCKII-mock). Lane 2 and 3 represent cells overexpressing P-gp (MDCKII-MDR1) and $\beta$-actin was used as a loading control.

MDR1 cells, the inhibitory effect of CsA on the P-gp mediated efflux of calcein, a representative substrate for P-gp, was measured. CsA significantly inhibited the calcein efflux and increased the cellular accumulation of calcein, whereas PAH had no effect on cellular calcein accumulation. Taken together, our MDCKII-MDR1 cell system was confirmed as appropriate for screening natural plant extracts with the potential to modulate P-gp function.

Using our system, we screened more than 800 natural plant extracts, in duplicate, for P-gp inhibition. Among these, we selected eight extracts that produced a greater than 3-fold increase in cellular calcein accumulation: Aloe ferox, Caesalpinia sappon, Dalbergia odorifera, Curcuma zedoariae rhizome, Zanthoxylum planisinum, Ageratum conyzoides, Curcuma aromatica, and Culcuma longa (Fig. 2).

We also screened the effects of three herbal constituents, curcumin, quercetin and flavones, and eight natural plant extracts on the P-gp mediated efflux of daunorubicin and vincristine, both of which are commonly prescribed anti-cancer drugs and representative P-gp substrates. As shown in Fig. 2, the most profound inhibition of P-gp activity was produced by the Curcuma aromatica extract, followed by Curcuma longa and Dalbergia odorifera extracts. Extracts of Aloe ferox, Curcuma zedoariae rhizome, Zanthoxylum planispinum and Ageratum conyzoides showed moderate inhibitory effects. Curcumin and quercetin exhibited similar inhibitory effects on P-gp mediated efflux, and flavones had a lesser effect compared with curcumin and quercetin (Fig. 2).

Effect of herbal constituents and plant extracts on cell viability

To confirm the safety of the herbal constituents and plant extracts in our screening system, we measured cell viability after incubation with the extracts. Cell viability was decreased in a concentration dependent manner after $48 \mathrm{~h}$ incubation 


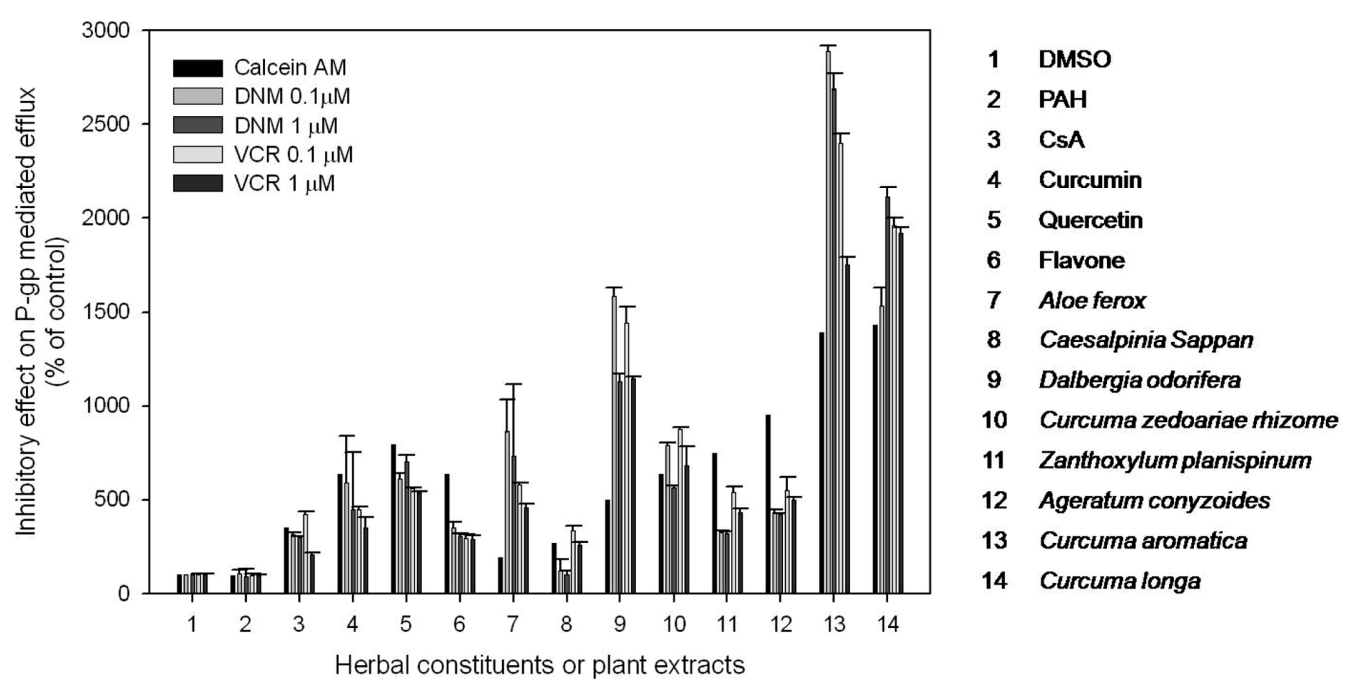

Figure 2. Cellular accumulation of $1 \mu \mathrm{M}$ calcein $\mathrm{AM},\left[{ }^{3} \mathrm{H}\right]$ daunorubicin $(0.1$ and $1 \mu \mathrm{M})$, and $\left[{ }^{3} \mathrm{H}\right]$ vincristine $(0.1$ and $1 \mu \mathrm{M})$ after incubation for $30 \mathrm{~min}$ in the presence of $10 \mu \mathrm{g} / \mathrm{mL} 3$ herbal constituents and 8 natural plant extracts. Each data point represents the mean \pm S.D. of three determinations.

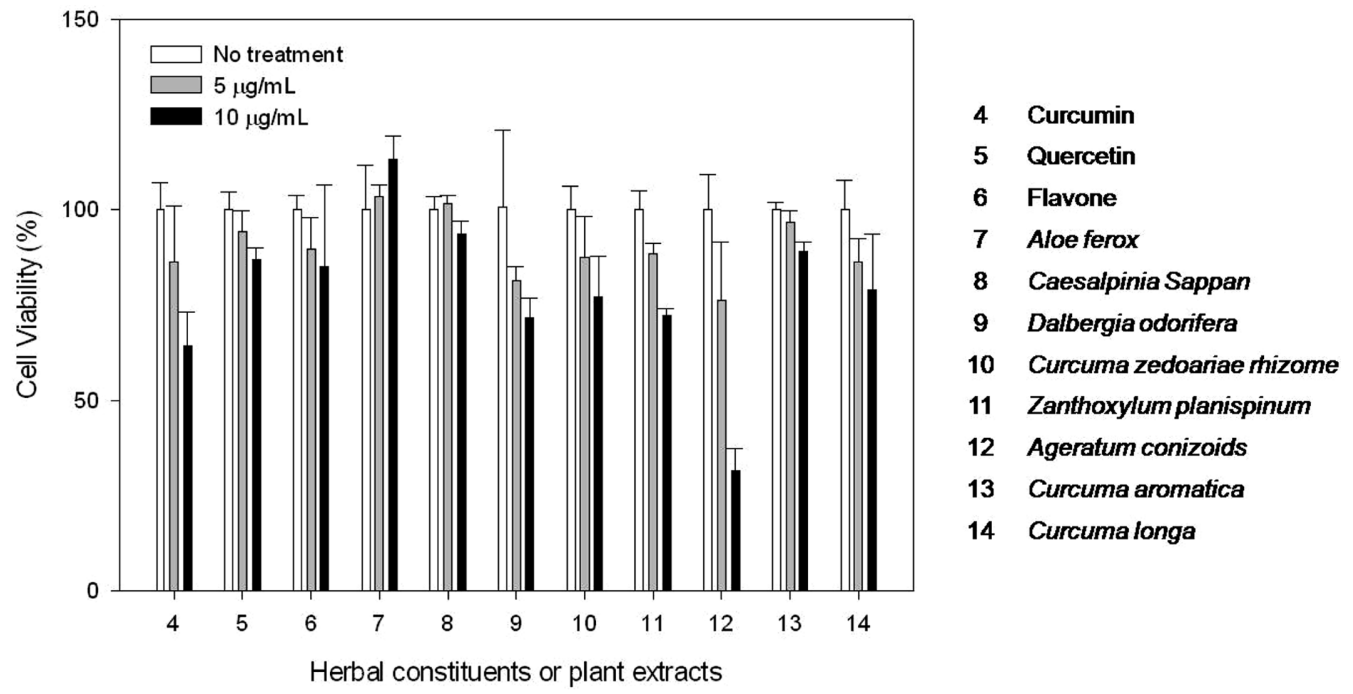

Figure 3. The effect of herbal constituent or natural plant extracts on cell viability in MDCKII-MDR1 cells. MTT assay was performed after the $48 \mathrm{~h}$ incubation of MDCKII-MDR 1 cells $\left(10^{4}\right.$ cells/well) in the absence and the presence of 5 and $10 \mu \mathrm{g} / \mathrm{mL}$ herb constituents or natural plant extracts.

with 5 and $10 \mu \mathrm{g} / \mathrm{mL}$ curcumin or Ageratum conyzoides extracts. Incubation with Darbergia odorifera, Curcumin zedoariae rhizome and Zanthoxylum planispinum extracts $(10 \mu \mathrm{g} / \mathrm{mL}$ each) resulted in $71.6 \%, 77.1 \%$, and $72.2 \%$ viability, respectively, compared with controls. Quercetin, flavone and the remaining extracts did not reduce viability by more than $20 \%$ (Fig. 3).

Taken together, these findings suggest that Curcuma aromatica is a promising MDR modulator, as it produced the greatest inhibition of P-gp activity on 3 different substrates, calcein, daunorubicin, and vincristine, with no significant cytotoxic effects at concentrations up to $10 \mu \mathrm{g} / \mathrm{mL}$. Dalbergia odorifera and Curcuma longa also showed significant P-gp inhibition and relatively low cytotoxicity.

\section{Curcuma aromatica sensitizes MDCKII-MDR1 cells to daunorubicin cytotoxicity}

We defined the resistance factor for daunorubicin as the ratio between $\mathrm{IC}_{50}$ value in P-gp overexpressing MDCKII-MDR1 cells and $\mathrm{IC}_{50}$ value in MDCKII-mock cells. $\mathrm{IC}_{50}$ values were calculated from the data in Fig. 4 by non-linear regression analysis using an inhibitory effect $\mathrm{E}_{\max }$ model. The resistance factor for daunorubicin alone was 39.5 but decreased to 3.3 when CsA was added. These results indicated that dauno- 
(A) MDCKII-mock

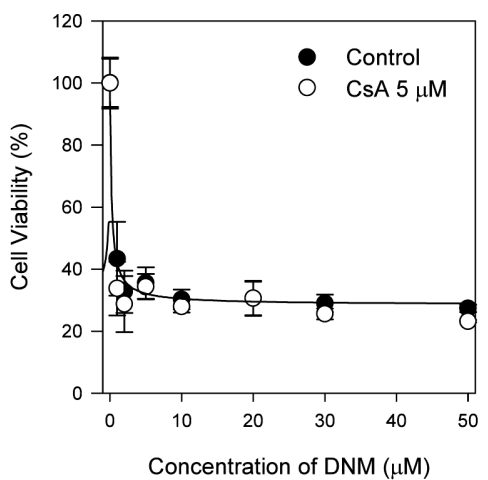

(B) MDCKII-MDR1

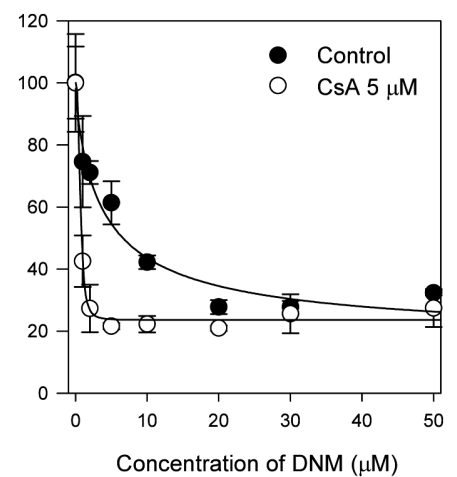

(C) MDCKII-MDR1

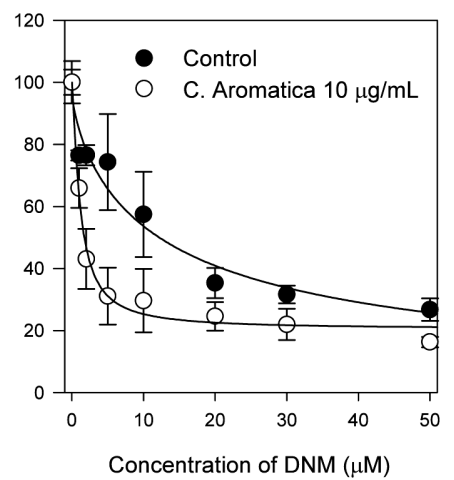

Figure 4. Chemosensitizing effect of Curcuma aromatica on the cytotoxicity of daunorubicin in MDCKII-mock and MDCKII-MDR1 cells. (A) Cytotoxicity of daunorubicin was measured by MTT assay in the presence and absence of $5 \mu \mathrm{M}$ CsA in MDCKII-mock cells with a concentration range of $0.01-50 \mu \mathrm{M}$ daunorubicin. (B) Cytotoxicity of daunorubicin was measured by MTT assay in the presence and absence of $5 \mu \mathrm{M}$ CsA in MDCKII-MDR1 cells with a concentration range of 0.01-50 $\mu \mathrm{M}$ daunorubicin. (C) Cytotoxicity of daunorubicin was measured by MTT assay in the presence and absence of $10 \mu \mathrm{g} / \mathrm{mL}$ Curcuma aromatica in MDCKII-MDR1 cells with a concentration range of 0.01-50 $\mu \mathrm{M}$ daunorubicin.

Table I. Changes in the Daunorubicin Sensitivity (IC $C_{50}$ values) to MDCKII-mock and MDCKII-MDR1 Cells in the Presence of P-gp Inhibitor, $5 \mu \mathrm{M}$ CsA and $10 \mu \mathrm{g} / \mathrm{mL}$ Curcuma Aromatica with a Concentration Range of 0.01 - $50 \mu \mathrm{M}$ Daunorubicin

\begin{tabular}{lccc}
\hline \hline & \multicolumn{3}{c}{$\mathrm{IC}_{50}(\mu \mathrm{M})$} \\
\cline { 2 - 4 } & $\begin{array}{c}\text { MDCKII- } \\
\text { mock }\end{array}$ & $\begin{array}{c}\text { MDCKII- } \\
\text { MDR1 }\end{array}$ & $\begin{array}{c}\text { Resistant } \\
\text { factor }\end{array}$ \\
\hline Control & 0.206 & 8.17 & 39.5 \\
CsA & 0.202 & 0.683 & 3.38 \\
Fold change & 1.01 & 11.9 & \\
(sensitivity increase) & & & \\
Control & & 13.5 & \\
Curcuma aromatica & & 1.13 & \\
$\begin{array}{l}\text { Fold change } \\
\text { (sensitivity increase) }\end{array}$ & & 11.9 & \\
\hline
\end{tabular}

rubicin resistance had occurred through P-gp overexpression and that the inhibition of P-gp by CsA chemosensitized the cells to daunorubicin (Table I).

Then we determined the daunorubicin cytotoxicity in the presence of $10 \mu \mathrm{g} / \mathrm{mL}$ Curcuma aromatica, as this extracts had produced the greatest P-gp inhibition without significant cytotoxicity. We compared the effect of Curcuma aromatica and that of CsA, which is one of the most commonly used P-gp inhibitors (Muzi et al., 2009; Liow et al., 2007). The sensitivity of P-gp overexpressing MDCKII-MDR1 cells to daunorubicin was increased 12-fold in the presence of CsA, because the inhibitory effect of CsA on P-gp function resulted in increased intracellular accumulation of daunorubicin, thereby enhancing drug sensitivity (Fig. 4A and B). The drug sensitivity of MDCKII-mock cells to daunorubicin was not changed by
Table II. Chemosensitizing Effect of Three Herbal Constituents and Eight Natural Plant Extracts (10 $\mu \mathrm{g} / \mathrm{mL}$ each) on the Daunorubicin Sensitivity (IC $C_{50}$ values) to MDCKII-MDR1 Cells with a Concentration Range of 0.01 - $50 \mu$ M Daunorubicin

\begin{tabular}{lcc}
\hline \hline & $\mathrm{IC}_{50}(\mu \mathrm{M})$ & $\begin{array}{c}\text { fold change } \\
\text { (sensitivity increase) }\end{array}$ \\
\hline Control & 10.4 & \\
Curcumin & 2.48 & 4.19 \\
Quercetin & 5.54 & 1.88 \\
Flavone & 26.6 & 0.39 \\
Aloe ferox & 52.0 & 0.20 \\
Caesalpinia sappan & 14.6 & 0.71 \\
Dalbergia odorifera & 19.3 & 0.54 \\
Curcuma zedoariae rhizome & 6.65 & 1.57 \\
Zanthoxylum planispin & 2.33 & 4.48 \\
Ageratum conyzoides & 1.87 & 5.56 \\
Curcuma aromatica & 0.922 & 11.2 \\
Curcuma longa & 2.57 & 4.05 \\
\hline
\end{tabular}

CsA. Similarly, Curcuma aromatica decreased the $\mathrm{IC}_{50}$ value for daunorubicin in MDCKII-MDR1 cells by 11.9-fold, indicating that the inhibition of P-gp by Curcuma aromatica sensitized MDCKII-MDR1 cells to daunorubicin by increasing cellular accumulation of this drug as a result of P-gp inhibition (Fig. 4C).

Chemosensitizing effects of herbal constituents and plant extracts

Next, we measured daunorubicin cytotoxicity in MDCKIIMDR1 cells in the presence and absence of three herbal constituents and eight plant extracts. As Shown in Table II, treat- 
ment with curcumin, quercetin, and the extracts of Xanthoxylum planispinum, Ageratum conyzoides, Curcuma aromatica and Curcuma longa sensitized MDCKII-MDR1 cells to daunorubicin cytotoxicity. In contrast, flavone and extracts of Aloe ferox and Dalbergia odorifera increased resistance to daunorubicin by more than 2 -fold.

\section{Discussion}

Drug resistance is a major obstacle in anti-cancer chemotherapy. Some cancers such as non-small cell lung cancer and rectal cancer are particularly resistant to initial drug treatment. On the other hand, many types of sensitive tumors respond well to chemotherapy early in treatment, but subsequently develop resistance (Choi, 2005). The transporter P-gp is thought to be responsible for $30 \%$ of MDR, making P-gp inhibition a promising strategy for overcoming MDR in cancer chemotherapy (Bansal et al., 2009).

Some flavonoids are reported to be specific inhibitors of Pgp. Flavonoids are particularly abundant in vegetables, fruits, and plant-derived beverages. Moreover, the average daily intake of total flavonoids was estimated to be more than $1 \mathrm{~g}$ per person in US (Zhang et al., 2004; Bansal et al., 2009). To search for similar plant products, we screened natural plant extracts for the ability to inhibit P-gp activity. Using intracellular accumulation of calcein, daunorubicin and vincristine as a marker for P-gp inhibition, we screened more than 800 plant extracts that are available in Korea and China and selected 8 for further investigation: Aloe ferox, Caesalpinia sappon, Dalbergia odorifera, Curcuma zedoariae rhizome, Zanthoxylum planisinum, Ageratum conyzoides, Curcuma aromatica and Culcuma longa. We also examined the effect of 3 herbal constituents, curcumin, quercetin and flavones, which are abundant in the extracts (Pilarski et al., 1998) and are reported to inhibit P-gp (Choi et al., 2004a; Choi et al., 2004b; Shin et al., 2006; Limtrakul, 2007; Pilarski et al., 1998). Since calcein, daunorubicin and vincristine, P-gp substrates used in the present study, are also substrates for MRP1 (Essodaigui et al., 1998; Renes et al., 1999; Versantvoort et al., 1994), the involvement of endogenous transporters (e.g. MRP1) could not be excluded although its contribution should be minimal.

Curcumin was identified from Curcuma zedoariae rhizome, Curcuma aromatica and Curcuma longa extracts using the LC/ MS/MS analysis (Lee et al., 2005; Ahn et al., 2008). Caesalpinia sappon, Dalbergia odorifera and Zanthoxylum planisinum were reported to contain high content of flavonoids, based on LC/MS/MS analysis and a flavonoid database search (Lee et al., 2005; Ahn et al., 2008). Using the similarity search of the flavonoid database, 3'-methoxy-4',5,7-trihydroxyflavone, 7,4'-dihydroxy-6-methoxyflavone, 3'-methoxyquercetin, and 5,7,4'-trihydroxy-3'-methoxyflavone were identified in Dalbergia odorifera extract; 2',4',6-trihydroxyflavanone and 3,3',4',7-tetrahydroxyflavone in Caesalpinia sappon extract; and 6,7-dimethoxy-5,3',4'-trihydroxyflavone in Zanthoxylum planisinum extract. Dalbergia odorifera extract also contained quercetin derivatives (Lee et al., 2005; Ahn et al., 2008).

Additional screening using daunorubicin and vincristine revealed that Curcuma aromatica extract produced the greatest P-gp inhibition and increased daunorubicin sensitivity by 11.2fold. This chemosensitizing effect was also produced by curcumin, quercetin and extracts of Zanthoxylum planispin, Ageratum conyzoides and Curcuma longa. Surprisingly, the presence of flavone, Aloe ferox and Dalbergia odorifera increased resistance to daunorubicin more than 2-fold, which are inconsistent with intracellular accumulation data. The reason for this discrepancy is currently unknown. The increased $\mathrm{IC}_{50}$ values of daunorubicin produced by flavone, Aloe ferox and Dalbergia odorifera may be a result of the antioxidant and anti-carcinogenic effects of these compounds overcoming the P-gp inhibitory effect (Fawole et al., 2010; Havsteen, 2002; Zhang et al., 2004).

Notably, the chemosensitizing effect of Curcuma aromatica was greater than that of curcumin, even though curcumin is a major component of Curcuma aromatica. Curcuma aromatica oil was reported to show chemoprotective effects in esophageal carcinogenesis and to reduce tumor size in hepatic carcinoma (Deng et al., 2004; Li et al., 2009; Wu et al., 2000). Therefore, synergism among the components of Curcuma aromatica may explain the greater effect of the extract compared with purified curcumin.

In conclusion, Curcuma aromatica extract was the most potent P-gp inhibitor among more than 800 natural plant extracts screened in this study and suggested to be further developed as a chemosensitizer through the in vivo experiments.

\section{Acknowledgments}

This work was supported by a grant (No. CBM34-B400001-01-00) from the Center for Biological Modulators of the 21st Century Frontier R\&D Program, Ministry of Science and Technology, Korea, and by the grant from Inje University, 2008.

\section{References}

Ahn, H.J., Kim, J.Y., Lee, C.H., Song, I.S., Liu, K.H., 2008. 
Screening of chemosensitizer candidates using natural extracts. J. Life Sci. 18, 1244-1248.

Bailey, D.G., Spence, J.D., Munoz, C., Arnold, J.M., 1991. Interaction of citrus juices with felodipine and nifedipine. Lancet 337, 268-269.

Bansal, T., Jaggi, M., Khar, R.K., Talegaonkar, S., 2009. Emerging significance of flavonoids as P-glycoprotein inhibitors in cancer chemotherapy. J. Pharm. Pharm. Sci. 12, 46-78.

Choi, C.H., 2005. ABC transporters as multidrug resistance mechanisms and the development of chemosensitizers for their reversal. Cancer Cell Int. 5, 30.

Choi, J.S., Choi, H.K., Shin, S.C., 2004a. Enhanced bioavailability of paclitaxel after oral coadministration with flavone in rats. Int. J. Pharm. 275, 165-170.

Choi, J.S., Jo, B.W., Kim, Y.C., 2004b. Enhanced paclitaxel bioavailability after oral administration of paclitaxel or prodrug to rats pretreated with quercetin. Eur. J. Pharm. Biopharm. 57, 313-318.

Dantzig, A.H., de Alwis, D.P., Burgess, M., 2003. Considerations in the design and development of transport inhibitors as adjuncts to drug therapy. Adv. Drug Deliv. Rev. 55, 133-150.

Deferme, S., Augustijns, P., 2003. The effect of food components on the absorption of P-gp substrates: a review. J. Pharm. Pharmacol. 55, 153-162.

Deferme, S., Van Gelder, J., Augustijns, P., 2002. Inhibitory effect of fruit extracts on P-glycoprotein-related efflux carriers: an invitro screening. J. Pharm. Pharmacol. 54, 1213-1219.

Deng, S.G., Wu, Z.F., Li, W.Y., Yang, Z.G., Chang, G., Meng, F.Z., Mo, L.L., 2004. Safety of Curcuma aromatica oil gelatin microspheres administered via hepatic artery. World J. Gastroenterol. 10, 2637-2642.

Efferth, T., Davey, M., Olbrich, A., Rucker, G., Gebhart, E., Davey, R., 2002. Activity of drugs from traditional Chinese medicine toward sensitive and MDR1- or MRP1-overexpressing multidrug-resistant human CCRF-CEM leukemia cells. Blood Cells Mol. Dis. 28, 160-168.

Essodaigui, M., Broxterman, H.J., Garnier-Suillerot, A., 1998. Kinetic analysis of calcein and calcein-acetoxymethylester efflux mediated by the multidrug resistance protein and P-glycoprotein. Biochemistry 37, 2243-2250.

Fawole, O.A., Amoo, S.O., Ndhlala, A.R., Light, M.E., Finnie, J. F., Van Staden, J., 2010. Anti-inflammatory, anticholinesterase, antioxidant and phytochemical properties of medicinal plants used for pain-related ailments in South Africa. J. Ethnopharmacol. 127, 235-241.

Havsteen, B.H., 2002. The biochemistry and medical significance of the flavonoids. Pharmacol. Ther. 96, 67-202.

Krishna, R., Mayer, L.D., 2000. Multidrug resistance (MDR) in cancer. Mechanisms, reversal using modulators of MDR and the role of MDR modulators in influencing the pharmacokinetics of anticancer drugs. Eur. J. Pharm. Sci. 11, 265-283.

Lee, J.S., Kim, D.H., Liu, K.H., Oh, T.K., Lee, C.H., 2005. Identification of flavonoids using liquid chromatography with electrospray ionization and ion trap tandem mass spectrometry with an MS/MS library. Rapid Commun. Mass Spectrom. 19, 3539-3548.

Li, Y., Wo, J.M., Liu, Q., Li, X., Martin, R.C., 2009. Chemoprotective effects of Curcuma aromatica on esophageal carcinogenesis. Ann. Surg. Oncol., 16 515-523.

Limtrakul, P., 2007. Curcumin as chemosensitizer. Adv. Exp. Med. Biol. 595, 269-300.

Liow, J.S., Lu, S., McCarron, J.A., Hong, J., Musachio, J.L., Pike, V.W., Innis, R.B., Zoghbi, S.S., 2007. Effect of a P-glycoprotein inhibitor, Cyclosporin $\mathrm{A}$, on the disposition in rodent brain and blood of the 5-HT1A receptor radioligand, [11C](R)(-)-RWAY. Synapse 61, 96-105.

Liscovitch, M., Lavie, Y., 2002. Cancer multidrug resistance: a review of recent drug discovery research. IDrugs 5, 349-355.

Marchetti, S., Mazzanti, R., Beijnen, J.H., Schellens, J.H., 2007. Concise review: Clinical relevance of drug drug and herb drug interactions mediated by the $\mathrm{ABC}$ transporter $\mathrm{ABCB} 1$ (MDR1, P-glycoprotein). Oncologist. 12, 927-941.

Muzi, M., Mankoff, D.A., Link, J.M., Shoner, S., Collier, A.C., Sasongko, L., Unadkat, J.D., 2009. Imaging of cyclosporine inhibition of P-glycoprotein activity using 11C-verapamil in the brain: studies of healthy humans. J. Nucl. Med. 50, 12671275.

Ozben, T., 2006. Mechanisms and strategies to overcome multiple drug resistance in cancer. FEBS Lett. 580, 2903-2909.

Pilarski, L.M., Yatscoff, R.W., Murphy, G.F., Belch, A.R., 1998. Drug resistance in multiple myeloma: cyclosporin A analogues and their metabolites as potential chemosensitizers. Leukemia 12, 505-509.

Renes, J., de Vries, E.G., Nienhuis, E.F., Jansen, P.L., Müller, M., 1999. ATP- and glutathione-dependent transport of chemotherapeutic drugs by the multidrug resistance protein MRP1. Br. J. Pharmacol. 126, 681-688.

Shin, S.C., Choi, J.S., Li, X., 2006. Enhanced bioavailability of tamoxifen after oral administration of tamoxifen with quercetin in rats. Int. J. Pharm. 313, 144-149.

Tan, B., Piwnica-Worms, D., Ratner, L., 2000. Multidrug resistance transporters and modulation. Curr. Opin. Oncol. 12, 450-458.

Thomas, H., Coley, H.M., 2003. Overcoming multidrug resistance in cancer: an update on the clinical strategy of inhibiting p-glycoprotein. Cancer Control 10, 159-165.

Versantvoort, C.H., Broxterman, H.J., Lankelma, J., Feller, N., Pinedo, H.M., 1994. Competitive inhibition by genistein and ATP dependence of daunorubicin transport in intact MRP overexpressing human small cell lung cancer cells. Biochem Pharmacol. 48, 1129-1136.

Wu, W.Y., Xu, Q., Shi, L.C., Zhang, W.B., 2000. Inhibitory effects of Curcuma aromatica oil on proliferation of hepatoma in mice. World J. Gastroenterol. 6, 216-219.

Zhang, S., Yang, X., Morris, M.E., 2004. Flavonoids are inhibitors of breast cancer resistance protein (ABCG2)-mediated transport. Mol. Pharmacol. 65, 1208-1216.

Zhou, S., Lim, L.Y., Chowbay, B., 2004. Herbal modulation of Pglycoprotein. Drug Metab. Rev. 36, 57-104.

J. Pharm. Invest., Vol. 40, No. 5 (2010) 